\title{
Study of pharmacokinetics and tissue distribution of liposomal brucine for dermal administration
}

This article was published in the following Dove Press journal:

International Journal of Nanomedicine

26 May 2011

Number of times this article has been viewed

\section{Bai-Can Yang' \\ Zhi-Feng Chu' \\ Sha Zhu' \\ Li-Jun Wang' \\ Yu-Hong Feng' \\ Feng-Hua $\mathrm{Li}^{\prime}$ \\ Chang-Sheng Liu² \\ Yuan Yuan ${ }^{2}$}

'Pharmacy Department of Traditional Chinese Medicine, Shanghai University of Traditional Chinese Medicine,

Shanghai, People's Republic of

China; ${ }^{2}$ Key Laboratory for Ultrafine Materials of Ministry of Education, and Engineering Research Center for Biomedical Materials of Ministry of Education, East China University of Science and Technology, Shanghai, People's Republic of China
Correspondence: Bai-Can Yang Pharmacy Department of Traditional Chinese Medicine, Shanghai University of Traditional Chinese Medicine, Shanghai 20I203, People's Republic of China $\mathrm{Tel} / \mathrm{Fax}+862151322208$

Email ybc2002@sina.com
Objective: To evaluate the pharmacokinetics and tissue distribution of liposomal brucine (LB) for dermal application.

Methods: Pharmacokinetics and tissue distribution were studied by in vivo animal testing. High performance liquid chromatography (HPLC) was used to detect the concentration of brucine in rats' skin, plasma and various tissues.

Results: After dermal administration, LB was absorbed rapidly in the skin and could be detected after 0.5 hours. After 36 hours, levels were too low to be detected. In plasma, levels were also too low to be detected after 36 hours. The concentration of LB reached $50 \%$ of the maximum in all tissues except the brain, peaking after 1.5 hours but still detectable after 12 hours.

Conclusion: The concentration of LB was high in skin at the application site. LB was quickly absorbed into tissues through the blood circulation and widely distributed throughout the whole body. There was no obvious toxicity and LB did not readily accumulate in tissues and organs. It showed local potency but low overall systemic toxicity.

Keywords: liposomal brucine, dermal administration, pharmacokinetics, tissue distribution

\section{Introduction}

Brucine is an alkaloid and exists mainly in the seeds of Strychnos nux-vomica L (Loganiaceae), ${ }^{1}$ which is widely used in China. The chemical structure of brucine is shown in Figure 1.

Brucine is known as an anti-inflammatory and analgesic drug for relieving pain due to arthritis and injuries. ${ }^{2}$ Its main pharmacodynamic actions are to relieve pain, reduce swelling, and promote circulation. Unfortunately, the potential use of brucine is severely limited due to its high incidence of side effects, including violent convulsions and even lethal poisoning. ${ }^{3}$ To overcome this problem, liposomal brucine (LB) for transdermal delivery was developed. The in vivo experiments we describe demonstrate that after encapsulation, brucine exhibits an apparent decrease in toxicity and/or an increase in therapeutic efficacy. ${ }^{46}$ The effectiveness of brucine for analgesia and relief of swelling improves after encapsulation in nanometer-sized liposomes, and it exhibits sustained release; targeting, ${ }^{7-10}$ local potency and low systemic toxicity. ${ }^{11,12}$ Although great progress has made in research on LB, so far the absorption, pharmacokinetics (PK), tissue distribution and metabolism of this new transdermal drug delivery system remain unknown.

This study investigated the pharmacokinetics and the final tissue distribution of transdermally administered LB. The concentration of LB in rats' skin, plasma and various tissues was measured by high performance liquid chromatography (HPLC). 


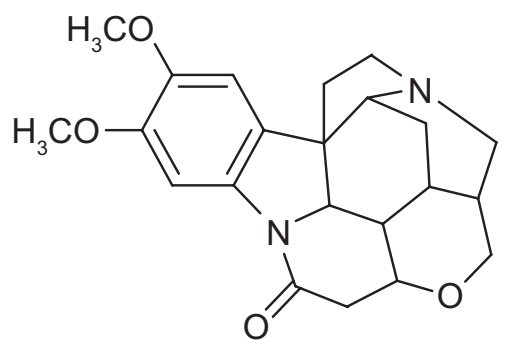

Figure I The structure of brucine.

\section{Materials and methods}

\section{Chemicals and reagents}

Standard brucine (Cat. No. 110706-200505) and strychnine (Cat. No. 11705-200306) (as the internal standard) were purchased from the Shanghai Institute of Biological Products (Shanghai, China). Brucine was purchased from Fluka (Sigma Aldrich, Buchs, Switzerland). Diethylamine, dichloromethane and ether (analytical grade) were obtained from Sinopharm Chemical Reagent (Shanghai, China). Methanol and acetonitrile (chromatographic grade) were obtained from Merck (Darmstadt, Germany). Water for HPLC was doubledistilled and all other reagents were analytical grade.

\section{Preparation of liposomes}

LB used in this study (95\%) was prepared by the East China University of Science and Technology (Shanghai, China). ${ }^{11}$ A modified ethanol-dripping method was used to prepare LB. ${ }^{12}$ An ethanol solution of lipid (lecithin: cholesterol $=6: 1 \mathrm{w} / \mathrm{w})$, sodium deoxycholate, Tween-80, and brucine (16:4:4:1, w/w) was dripped into mannitol solution $(5.3 \mathrm{mg} / \mathrm{mL})$. The ratio of the ethanolic-lipid phase to the aqueous phase was 1:9 (v/v) in the final suspension. The suspension was then sonicated (45 W; Shanghai Kedao Ultrasonic Instrument Co, Shanghai, China) in an ice water-bath for 20 minutes and freeze-dried for 72 hours. The dry powder was stored at $-18^{\circ} \mathrm{C}$ in a freezer. The dry powder was rehydrated and sonicated for 3 minutes prior to application. ${ }^{11}$

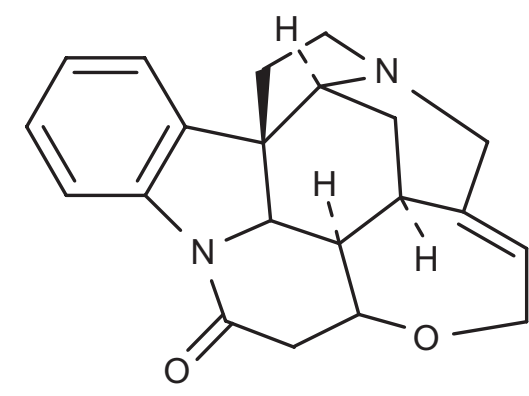

Figure 2 The structure of strychnine.

\section{Animals}

Healthy Sprague-Dawley (SD) rats of both sexes, weighing 180-220 g, were provided by the Experimental Animals Center of Fudan University (Shanghai, China). On arrival, the animals were acclimated for 7 days. The animals were housed in standard cages, maintained at a temperature of $22 \pm 2^{\circ} \mathrm{C}$ and $40 \%-70 \%$ relative humidity with 12 hour light/ dark cycles, and provided with fresh water and standardized diets ad libitum, unless otherwise noted. The animal tests were performed according to the Principles of Laboratory Animal Care and Use in Research, Ministry of Health (Beijing, China). All animal experiments were approved by the Animal Ethics Committee, Ministry of Health (Beijing, China).

\section{Sample collection and treatment}

One hundred and forty healthy SD rats were divided into two groups according to sex. LB suspension was smeared on the skin at the hypogastric zone at a dose of $6 \mathrm{mg} / \mathrm{kg}$ (concentration of brucine administrated was $1 \mathrm{mg} / \mathrm{kg}$ ).

\section{Skin PK study}

Twelve hours before administration, the rats were shaved in the hypogastric zone. SD rats were anesthetized with urethane (concentration $25 \%$, dose rate $0.4 \mathrm{~mL} / 100 \mathrm{~g}$ ). About $3 \mathrm{~cm} \times 3 \mathrm{~cm}$ of skin was cut at $0.5,2,4,8,12,14,16,18$, $20,22,24,28$ and 36 hours post-dosing according to a preset schedule.

\section{Plasma PK study}

1.5-2.0 $\mathrm{mL}$ blood samples were collected from the abdominal aorta at $0.5,2,4,8,12,14,16,18,20,22,24,28$ and 36 hours after intravenous injection of brucine phosphate buffered saline solution or LB suspension, to study the sustained-release properties of the liposome delivery method.

\section{Treatment}

Skins were rinsed with water to remove remaining traces of blood before handling. A $0.5 \mathrm{~g}$ skin sample was homogenized at $0^{\circ} \mathrm{C}$. Subsequently, $1 \mathrm{~mL}$ homogenate or $0.2 \mathrm{~mL}$ plasma was added to $20 \mu \mathrm{L}$ internal standard (strychnine) and $2 \mathrm{~mol} / \mathrm{L} \mathrm{NaOH}$. The solutions were vortex-mixed for 10 minutes at 12,000 rpm after extracting with diethyl ether: methylene chloride (2:1). The upper organic layer was evaporated to dryness in a vacuum drying oven. The residue dissolved in the mobile phase was vortex-mixed for 10 minutes at $12,000 \mathrm{rpm}$. From this, $20 \mu \mathrm{L}$ supernatant was used for PK evaluation. 


\section{Tissue distribution study}

The brain, liver (superior lobe), kidney, heart, lung, spleen and femoribus internus muscle were removed from each anesthetized animal by gross dissection at $0.5,1,1.5,2,4$, 8 and 12 hours after dermal administration. Tissues were rinsed with water to remove remaining traces of blood before handling.

For each animal, $0.5 \mathrm{~g}$ of each tissue type was homogenized at $0^{\circ} \mathrm{C}$, and then $1 \mathrm{~mL}$ homogenate was added into $100 \mu \mathrm{L}$ ammonia water and shaken slightly. Then $5 \mathrm{~mL}$ chloroform was added into the tube. The homogenate was vortex-mixed for 1 minute at $2900 \mathrm{rpm}$. Then the solution was sonicated for 40 minutes. The under layer (chloroform) was collected and was volatilized in a vacuum drying oven after incubating for 4 hours at $60^{\circ} \mathrm{C}$. The residue dissolved in the mobile phase was vortex-mixed for 10 minutes at $12,000 \mathrm{rpm}$. Subsequently $20 \mu \mathrm{L}$ of the supernatant was used for chromatographic analysis. The content of brucine in each tissue sample was qualitatively and quantitatively analyzed by RP-HPLC.

\section{Instrumentation and chromatographic conditions}

HPLC was performed on an Agilent 1200 series system (Agilent Technologies, Waldbronn, Germany) equipped with a binary pump (G1312A), a thermostatically controlled column compartment and a UV detector. The separation of skin and plasma was achieved with a Thermo Hypersil ODS $\mathrm{C}_{18}$ Column (250 mm $\times 4.6 \mathrm{~mm}, 5 \mu \mathrm{m}$; Hypersil, Thermo Scientific, Waltham, MA) and $\mathrm{CH}_{3} \mathrm{OH}: \mathrm{H}_{2} \mathrm{O}:\left(\mathrm{C}_{2} \mathrm{H}_{5}\right)_{2} \mathrm{NH}$ $(55: 45: 0.2, \mathrm{v} / \mathrm{v})$ was used as the mobile phase. The tissue distribution study was carried out using a Discovery C18 Column $(250 \mathrm{~mm} \times 4.6 \mathrm{~mm}, 5 \mu \mathrm{m}$; Supelcosil, Sigma Aldrich, St Louis, MO). Acetonitrile: $10 \mathrm{mmol} / \mathrm{L}$ sodium heptanesulfonate balanced mixed with $20 \mathrm{mmol} / \mathrm{L}$ potassium dihydrogen phosphate ( $\mathrm{pH}$ was adjusted to 2.8 by $10 \%$ $\left.\mathrm{H}_{3} \mathrm{PO}_{4}\right)(21: 79 \mathrm{v} / \mathrm{v})$ was used as the mobile phase. Column temperature was at $30^{\circ} \mathrm{C}$ and flow speed was $1 \mathrm{~mL} /$ minute with wavelength set at $260 \mathrm{~nm}$.

\section{Parameter calculation}

The active components in skin and tissue were analyzed by comparing the chromatographs of skin and tissue samples after the rats were given brucine standard preparation, with blank skin samples. The composition of plasma samples after transdermal drug delivery was analyzed by comparing the sample chromatographs with those of brucine standard preparations and control blood samples.
Brucine concentration and concentration-time response was calculated in skin using the DAS program. Pharmacokinetics parameters were calculated using the statistical moment method. Data from tissue samples was analyzed using mean \pm SD (standard deviation) and the difference between each group was compared using the variance. All statistical analysis used SPSS software (v 12.0; SPSS, Inc, Chicago, IL).

\section{Results and discussion Characterization of liposomes}

The average size of the liposomes was between 25 and $110 \mathrm{~nm}$, and the mean diameter was $55.4 \mathrm{~nm}$, indicating a narrow population distribution. The encapsulation efficiency (EE) of LB determined by gel filtration was $71.95 \% \pm 2.65 \%(\mathrm{n}=4)(\mathrm{EE}=$ [total drug-unencapsulated $\mathrm{drug}] /$ total drug $\times 100 \%$ ). The average zeta-potential was $-39.5 \mathrm{eV}$.

\section{HPLC determination}

Figures 3 and 4 illustrate the chromatography of brucine. It can be seen that there were no peaks at the same retention time in the blank sample as in the reference substance. The peak of brucine could be separated from other components and there were no endogenous peaks interfering with brucine.

Figure 5 shows the HPLC chromatographs of brucine extracted from different tissues after transdermal administration. As shown, there were no new metabolites observed in the tissues. This implied that the chromatographic conditions used could be applied to the assay of brucine in different tissues in the following study.

\section{Skin PK study}

Figure 6 shows the concentration-time curve of brucine levels in rat skin. It has been found that LB can be absorbed rapidly after administration and can be measured after 0.5 hours. Brucine concentration in skin changed over time, declining to below the limits of measurement (LOQ, $0.1 \mu \mathrm{g} / \mathrm{mL}$ ) by 36 hours after administration.

Tables 1 and 2 present the pharmacokinetics parameters calculated from female and male rat skin experiments, respectively. From Table 1, it can be seen that the half-life of LB in female rat skin was about 3.1 hours. The drug content in skin reached a peak of $7.39 \mu \mathrm{g} / \mathrm{g}$ after 15.6 hours. From Table 2, it can be seen that the half-life of brucine liposomes in male rats' skin was about 3.6 hours. Brucine concentration in skin peaked at $5.99 \mu \mathrm{g} / \mathrm{g}, 16$ hours after administration. 
A

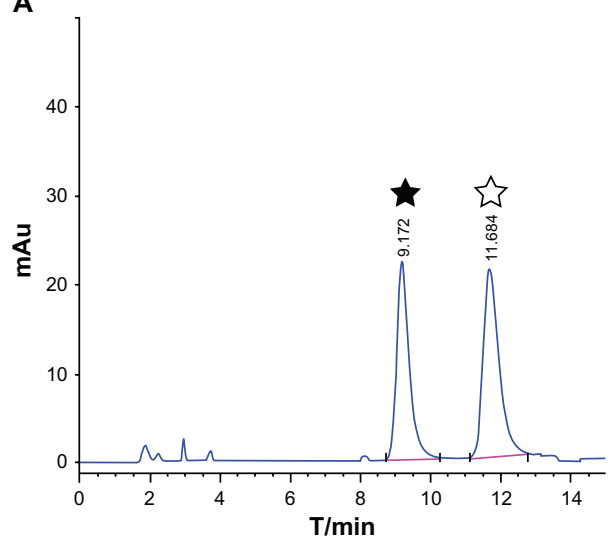

C

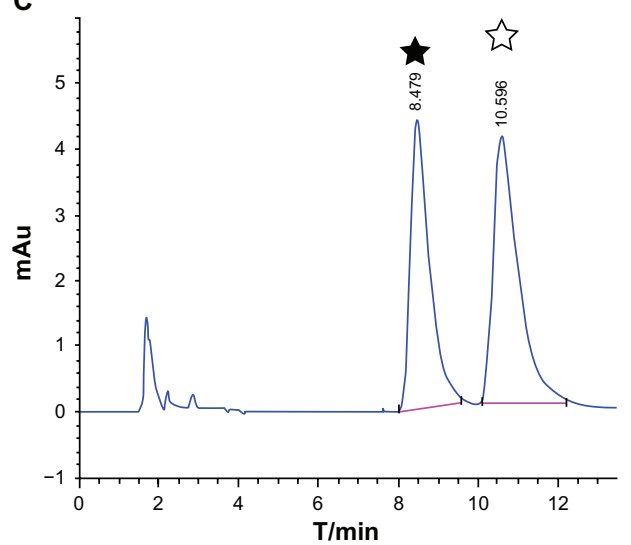

B

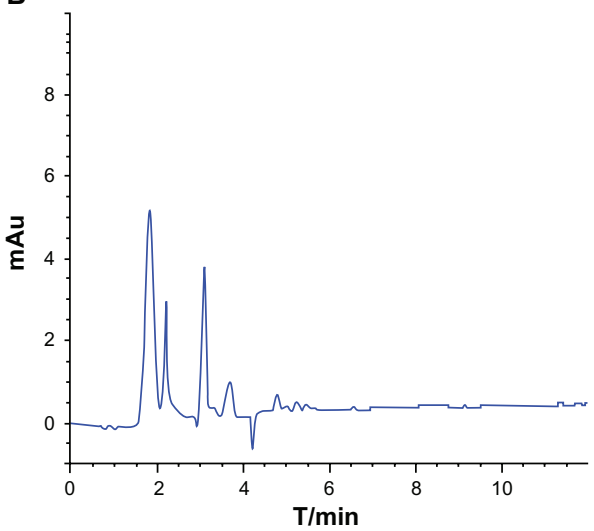

D

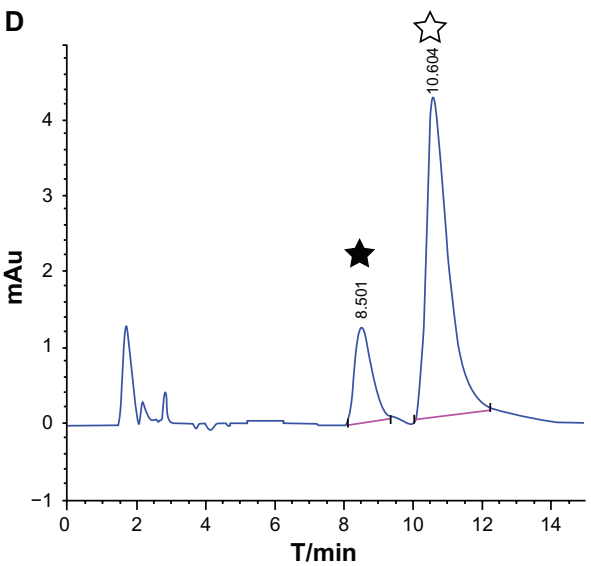

Figure 3 HPLC chromatographs of brucine.

Notes: A, Standard; B, Blank Skin; C, Blank Skin + Standard; D, Skin containing brucine; $\star$, Brucine; $\downarrow$, Internal Standard: Strychnine.

A

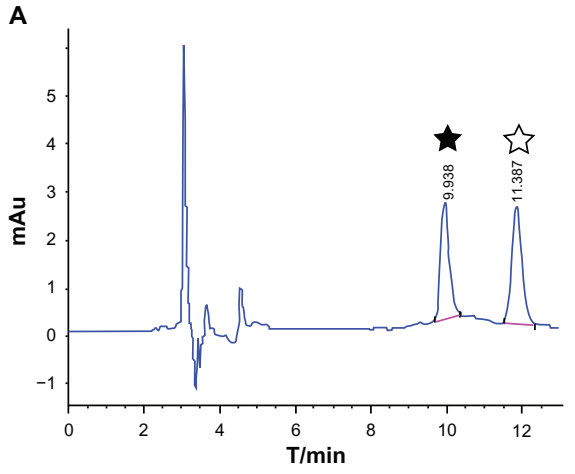

C

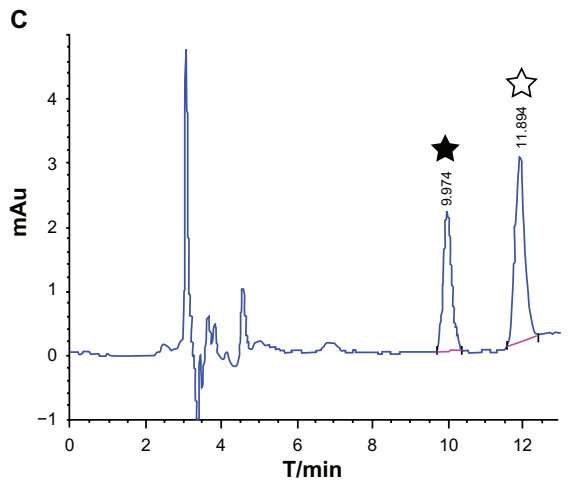

B

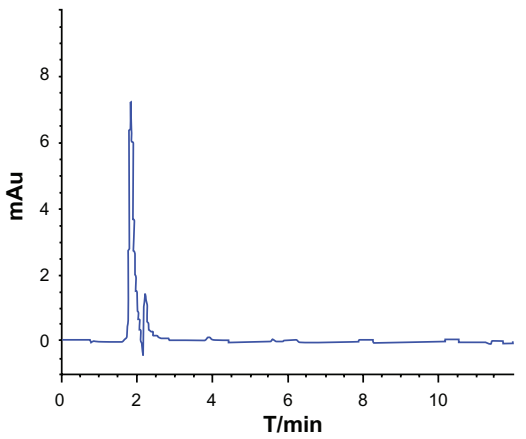

D

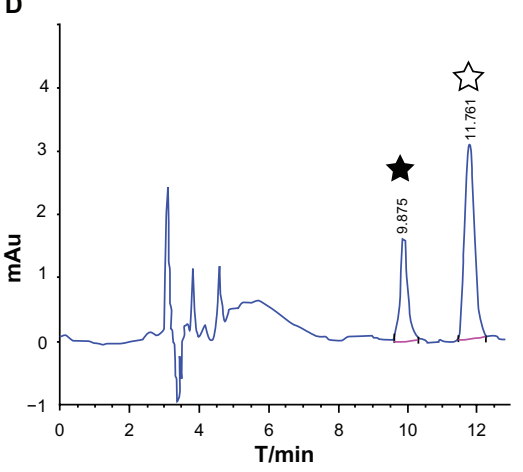

Figure 4 HPLC chromatographs of brucine.

Notes: A, Standard; B, Blank Plasma; C, Blank Plasma + Standard; D, Plasma containing brucine; $\star$, Brucine; is, Internal Standard: Strychnine. 


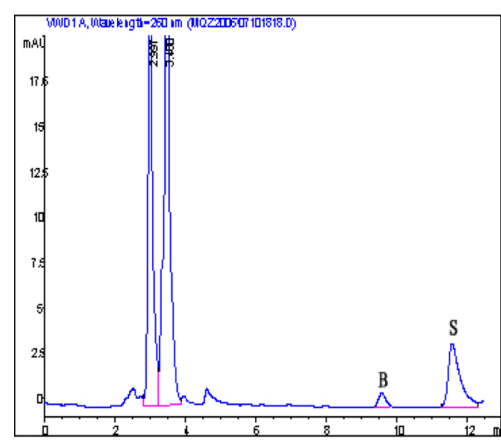

A

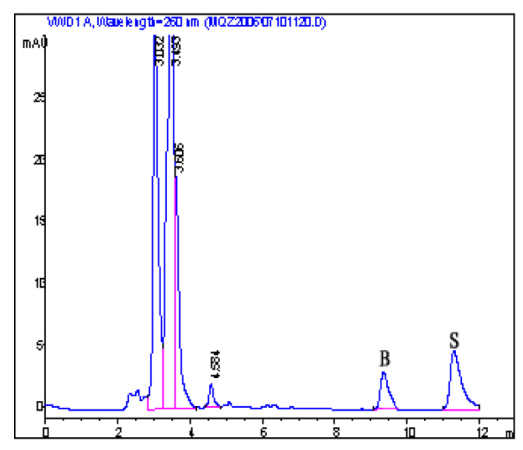

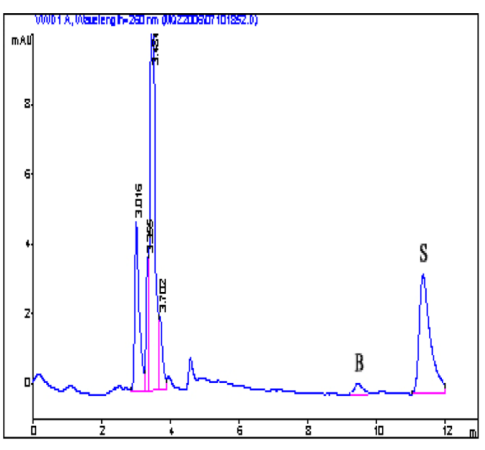

B
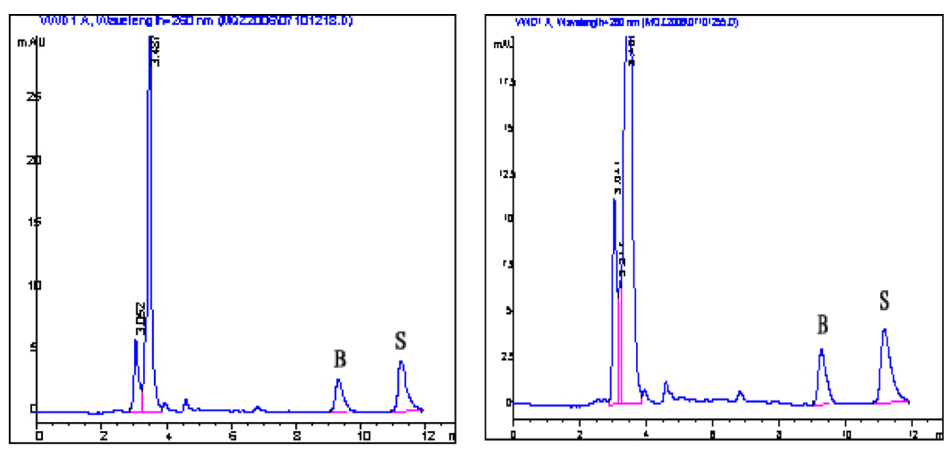

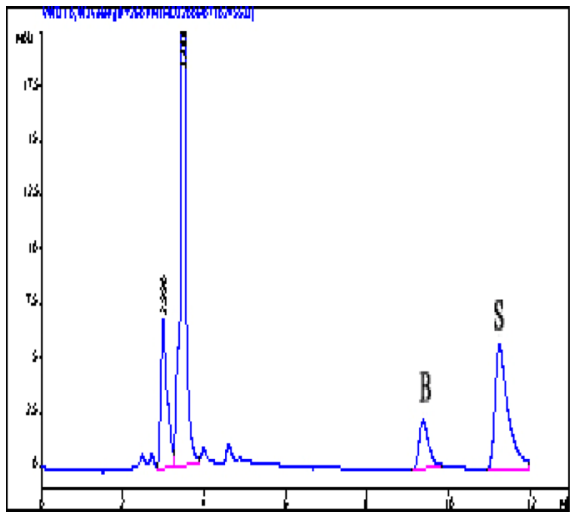

Figure 5 HPLC chromatographs of brucine in each tissue sample after administration.

Notes: A, Liver; B, Spleen; C, Kidney; D, Heart; E, Brain; F, Lung; G, Muscle; B, Brucine; S, Internal Standard: Strychnine.
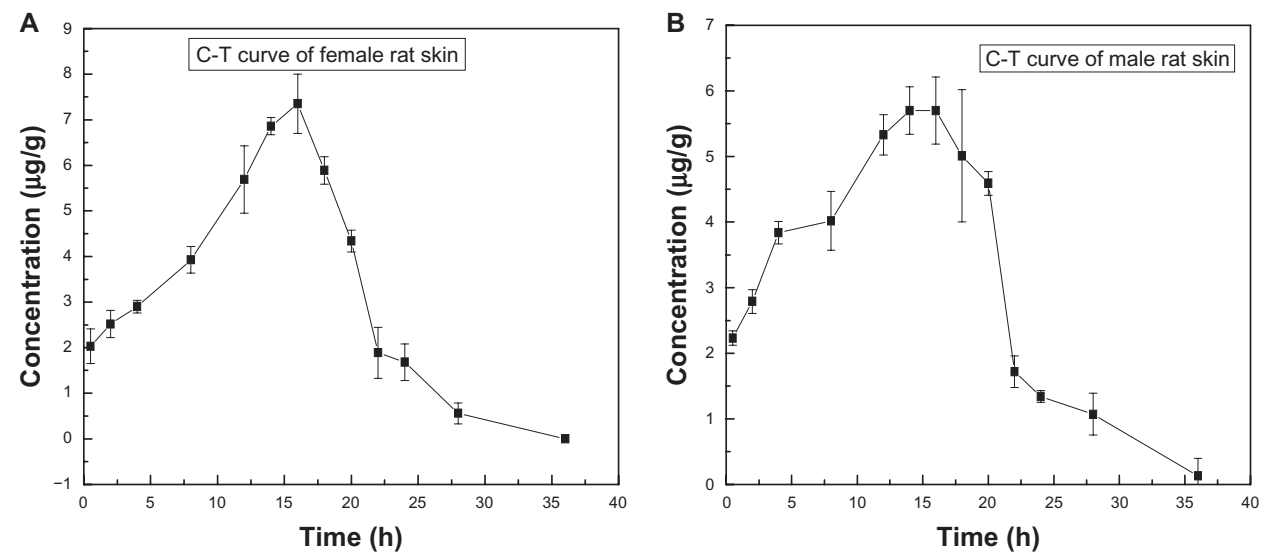

Figure 6 Concentration-time curve of brucine content in male and female rats $(n=5)$.

Notes: A, C-T Curve Female rat skin; B, C-T Curve of Male rat skin.

Abbreviation: $\mathrm{C}-\mathrm{T}$, concentration-time. 
Table I PK parameters for brucine in female rats' skin $(n=5)$

\begin{tabular}{llll}
\hline Parameter & Unit & Mean & SD \\
\hline $\mathrm{t}_{1 / 2 \mathrm{z}}$ & hours & 3.14 & $0.3 \mathrm{I}$ \\
$\mathrm{t}_{\max }$ & hours & 15.60 & 0.89 \\
$\mathrm{C}_{\max }$ & $\mathrm{mg} / \mathrm{L}$ & 7.39 & 0.61 \\
$\mathrm{CLz} / \mathrm{F}$ & $\mathrm{L} /$ hours $/ \mathrm{kg}$ & 0.055 & 0.003 \\
$\mathrm{Vz} / \mathrm{F}$ & $\mathrm{L} / \mathrm{kg}$ & 0.248 & 0.03 \\
$\mathrm{MRT}(0-\infty)$ & hours & 13.83 & 0.23 \\
$\operatorname{MRT}(0-\mathrm{t})$ & hours & 13.71 & 0.24 \\
$\mathrm{AUC}(0-\mathrm{t})$ & $\mathrm{mg} / \mathrm{L} \times$ hours & 109.40 & 5.50 \\
$\mathrm{AUC}(0-\infty)$ & $\mathrm{mg} / \mathrm{L} \times$ hours & 109.86 & 5.48 \\
\hline
\end{tabular}

\section{Note:*}

Abbreviations: $A U C$, area under the curve; $C L z$, clearance; $C_{\max }$, maximum concentration; F, availability; MRT, mean residence time; PK, pharmacokinetics; $\mathrm{t}_{1 / 2}$, biological half-life; $\mathrm{t}_{\max }$, time to reach $\mathrm{C}_{\max } ; \mathrm{Vz}$, volume of distribution during terminal $(Z)$ phase.

Based on the above results, it can be concluded that the skin had a typical reservoir effect for liposome-encapsulated brucine. We found a sex difference in drug absorption among rats after transdermal delivery. For this reason, separate time-concentration curves were constructed for males and females. Pharmacokinetic parameters were calculated by statistical moments according to the noncompartment model. The concentration peak of LB in female rats' skin was higher than that in male rats' skin. However the half-life of LB in male rats' skin was about 3.6 hours, which was longer than that in females (3.1 hours). This difference in the level of LB in the skin of the two sexes may be related to hormones, which often influence drug absorption.

\section{Plasma PK study}

Drug concentration in plasma was determined after LB was given by dermal administration. Brucine could not be detected in the plasma 36 hours after dermal administration. For accuracy, we studied the plasma pharmacokinetics of LB and normal brucine after intravenous injection.

Table 2 PK parameters for brucine in male rats' skin $(n=5)$

\begin{tabular}{llll}
\hline Parameter & Unit & Mean & SD \\
\hline $\mathrm{t}_{\mathrm{I} / 2 \mathrm{z}}$ & hours & $3.60^{*}$ & $\mathrm{I} .13$ \\
$\mathrm{t}_{\max }$ & hours & 16.00 & $1.4 \mathrm{I}$ \\
$\mathrm{C}_{\max }$ & $\mathrm{mg} / \mathrm{L}$ & $5.9 *^{*}$ & 0.33 \\
$\mathrm{CLz} / \mathrm{F}$ & $\mathrm{L} /$ hours/kg & 0.055 & 0.003 \\
$\mathrm{Vz} / \mathrm{F}$ & $\mathrm{L} / \mathrm{kg}$ & 0.283 & $0.07 \mathrm{I}$ \\
$\operatorname{MRT}(0-\mathrm{t})$ & hours & 13.63 & 0.46 \\
$\operatorname{MRT}(0-\infty)$ & hours & 13.96 & 0.95 \\
$\mathrm{AUC}(0-\mathrm{t})$ & $\mathrm{mg} / \mathrm{L} \times$ hours & 107.37 & 4.53 \\
$\mathrm{AUC}(0-\infty)$ & $\mathrm{mg} / \mathrm{L} \times$ hours & 108.68 & 6.20 \\
\hline
\end{tabular}

Note: $* P<0.05$ (compared with female).

Abbreviations: $A U C$, area under the curve; $C L z$, clearance; $C_{\max }$, maximum concentration; F, availability; MRT, mean residence time; PK, pharmacokinetics; $t_{1 / 2}$, biological half-life; $\mathrm{t}_{\max }$, time to reach $\mathrm{C}_{\max } ; \mathrm{Vz}$, volume of distribution during terminal (Z) phase.

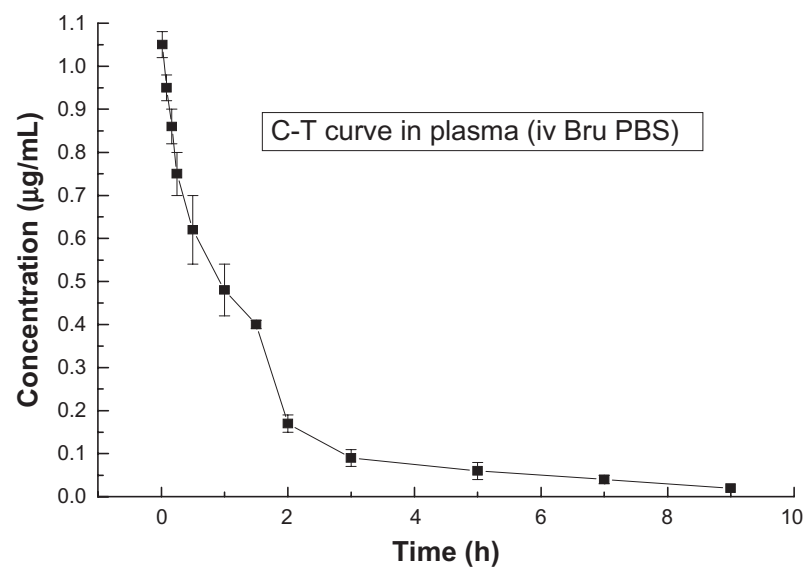

Figure 7 Concentration-time curve of brucine in plasma after intravenous injection of brucine solution $(n=5)$.

Abbreviations: Bru, brucine; C-T, concentration-time; iv, intravenous injection; PBS, phosphate buffered saline.

Figures 7 and 8 show the concentration-time curves for LB and normal brucine in rats' plasma. Tables 3 and 4 present the corresponding pharmacokinetics parameters.

It can be seen that the half-life of normal brucine solution was about 0.9 hours and the half-life of LB was about 2.4 hours. The half-life of LB was considerably longer than that of normal brucine. We believe this phenomenon could be attributable to the sustained-release effect associated with liposomes.

\section{Tissue distribution study}

The concentrations of LB in different tissues were determined $0.5,1,1.5,2,4,8$ and 12 hours after administration. It was found that brucine could distribute widely in different

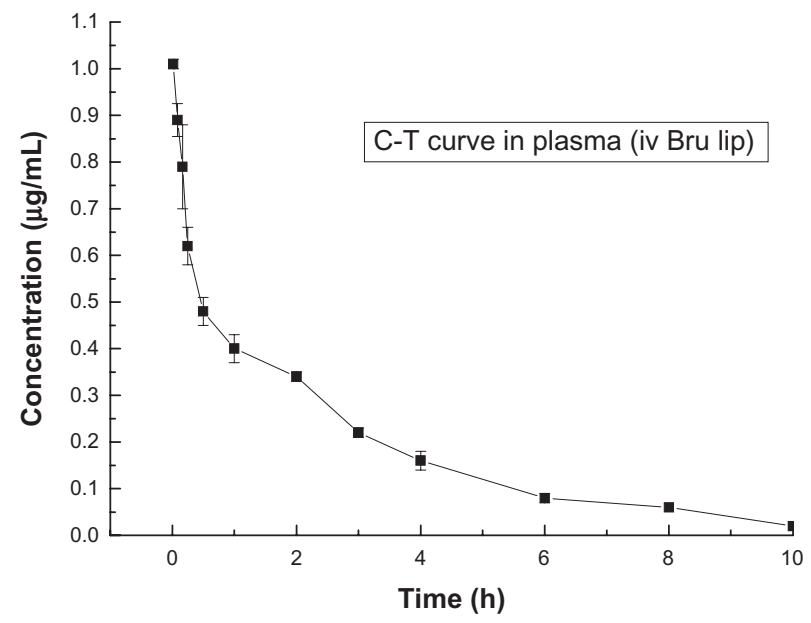

Figure 8 Concentration-time curve of brucine in plasma after intravenous injection of $\operatorname{LB}(n=5)$.

Abbreviations: Bru, brucine; C-T, concentration-time; iv, intravenous injection; LB, liposomal brucine; lip, liposome. 
Table 3 Plasma PK parameters, iv of brucine $(n=5)$

\begin{tabular}{llll}
\hline Compartment parameter & Unit & Mean & SD \\
\hline $\mathrm{t}_{1 / 2}$ & hours & 0.88 & 0.04 \\
$\mathrm{Ke}$ & $\mathrm{I} / \mathrm{hours}$ & 0.79 & 0.04 \\
$\mathrm{VI}$ & $\mathrm{L} / \mathrm{kg}$ & 4.92 & 0.28 \\
$\mathrm{CL}$ & $\mathrm{L} / \mathrm{hours} / \mathrm{kg}$ & 3.88 & 0.13 \\
$\mathrm{AUC}(0-\mathrm{t})$ & $\mathrm{mg} / \mathrm{L} \times$ hours & 1.15 & 0.05 \\
$\mathrm{AUC}(0-\infty)$ & $\mathrm{mg} / \mathrm{L} \times$ hours & 1.29 & 0.04 \\
\hline
\end{tabular}

Abbreviations: $\mathrm{AUC}$, area under the curve; $\mathrm{CL}$, clearance; iv, intravenous injection $\mathrm{K}_{\mathrm{e}}$, elimination rate constant; PK, Pharmacokinetics; $\mathrm{VI}$, central volume.

organs and tissues but the concentrations differed with the organs and tissues involved. The concentrations in organs and tissues showed concentration-time effects for the dermally administered product.

Figure 9 shows brucine concentration over time in rat tissues after dermal administration of LB. After dermal administration, LB distributed widely and could be detected in the liver, heart, spleen, lung, kidney, brain and muscle tissue.

As shown in Figure 9, with the exception of heart and brain, the concentration rose to $50 \%$ of the maximum concentration in all tissues after 0.5 hours and peaked at 1.5 hours. It decreased to half of the maximum concentration after 2 hours. The concentration increased slightly at 4 hours, then declined gradually. It could not be measured after 12 hours. These data showed LB was absorbed quickly but did not accumulate in vivo. The peak values of brucine in lung and muscle occurred after 1.5 hours and later concentrations were lower than those in liver, kidney and spleen. The concentration was higher in kidney than in liver and lung and the rate of absorption was faster. These results suggested brucine was absorbed well but excreted quickly. The concentration trend in muscle showed characteristics of

Table 4 Plasma PK parameters, iv of LB $(n=5)$

\begin{tabular}{llll}
\hline Compartment parameter & Unit & Mean & SD \\
\hline $\mathrm{t}_{1 / 2 \alpha}$ & hours & 0.12 & 0.04 \\
$\mathrm{t}_{1 / 2 \beta}$ & hours & 2.37 & 0.48 \\
$\mathrm{VI}$ & $\mathrm{L} / \mathrm{kg}$ & 4.54 & 0.05 \\
$\mathrm{CL}$ & $\mathrm{L} /$ hours $/ \mathrm{kg}$ & 2.62 & 0.19 \\
$\mathrm{AUC}(0-\mathrm{t})$ & $\mathrm{mg} / \mathrm{L} \times$ hours & 1.39 & 0.06 \\
$\mathrm{AUC}(0-\infty)$ & $\mathrm{mg} / \mathrm{L} \times$ hours & 1.92 & 0.15 \\
$\mathrm{KIO}$ & $\mathrm{I} /$ hours & 0.58 & 0.04 \\
$\mathrm{KI} 2$ & I/hours & 2.93 & 2.82 \\
$\mathrm{~K} 2 \mathrm{I}$ & I/hours & 3.23 & $\mathrm{I}$ \\
\hline
\end{tabular}

Abbreviations: $\mathrm{AUC}$, area under the curve; $\mathrm{CL}$, clearance; iv, intravenous injection; KI0-12, microconstants; LB, liposomal brucine; PK, Pharmacokinetics; VI, central volume. rapid absorption and excretion. However the concentration in muscle was lower than in other tissues (except the brain).

A similar trend for LB concentration distribution was observed over time in a range of tissues after dermal administration. The concentration of brucine increased at first and then declined over time, but the concentrations differed between types of tissue.

Based on these data, LB showed tissue selectivity. The concentrations in liver, kidney, spleen and lung were higher than in other tissues. We think this may be related to the sequestration effect associated with phagocytic cells. It is well established that phagocytes, which are abundant in the reticuloendothelial system, in liver, kidney, spleen and lung tissues, can trigger the process of phagocytic recognition and subsequent blood clearance. Brucine can be quantified in rat brain tissue, and we postulate that LB passes through the blood-brain barrier and plays a role in the central nervous system after dermal administration. LB does not appear to cause toxicity in the brain or the kidneys.

After dermal administration, LB can rapidly enter tissues. The concentrations in some organs were higher than that in blood. However, the concentration was lower than for normal brucine. It can be hypothesized that LB would cause less toxicity to organs than normal brucine. LB could be effective for pain relief and as an anti-inflammatory agent while avoiding the side effects associated with normal brucine. This established LB as having targeted, sustained release, with locally potent therapeutic effects, and low systemic toxicity. This study suggests that clinical use of LB is feasible, thus avoiding problems associated with traditional forms of brucine. This provides a basis for new analgesic preparations using Strychnos nux-vomica $L$.

\section{Conclusion}

A previous study ${ }^{13}$ showed the analgesic and anti-inflammatory properties of LB after dermal administration and established there were no apparent side effects locally or systemically.

This study of skin pharmacokinetics showed that after dermal administration, the concentration of LB in rats' skin changed over time. LB encapsulated in liposomes could form a sustained release system in skin. The plasma pharmacokinetics study showed that 36 hours after dermal administration, brucine could not be detected in plasma, indicating that LB was accumulated mainly in local skin and minimally in blood circulation. 


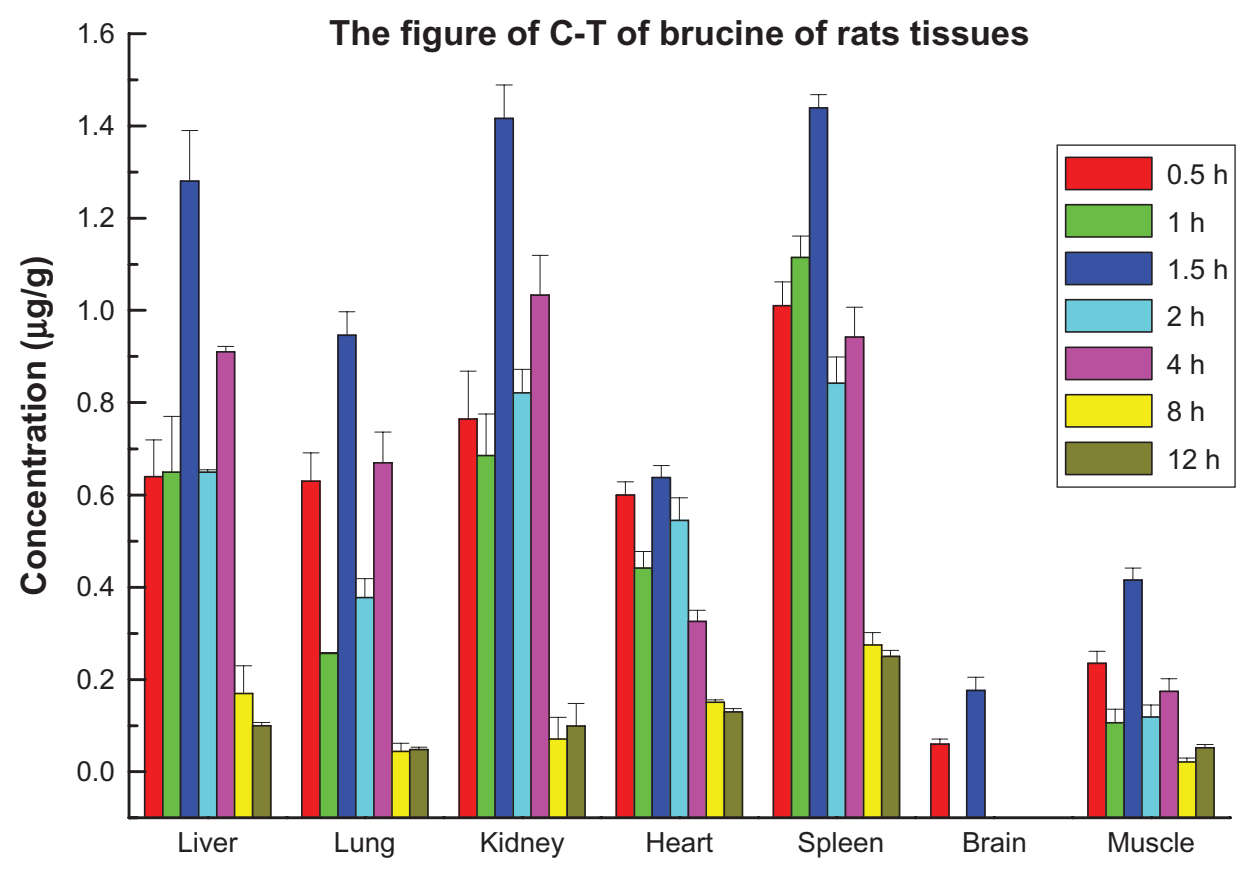

Figure 9 Distribution of LB in rat tissues over time.

Abbreviations: C-T, concentration-time; LB, liposomal brucine.

\section{Acknowledgment}

Project supported by Shanghai Nanotechnology Special Foundation (No 0352nm115 and No 0552nm007).

\section{Disclosure}

The authors report no conflicts of interest with this work.

\section{References}

1. Chinese Pharmacopoeia Committee. Pharmacopoeia of the People's Republic of China Volume I. Beijing: Chemical Industry Press; 2005.

2. Yin W, Wang TS, Yin FZ, et al. Analgesic and anti-inflammatory properties of brucine and brucine N-oxide extracted from seeds of Strychnos nux-vomica. J Ethnopharmacol. 2003;88:205-214.

3. Zhu YN, Bao MZ, Chen D, et al. Study on the toxicity of brucine in mice. Henan Med Res. 1994;3(2):107-109. Chinese.

4. Srinath P, Vyas SP, Diwan PV. Preparation and pharmacodynamic evaluation of liposomes of indomethacin. Drug Dev Ind Pharm. 2000;26: 313-321.

5. Singh AK, Das J. Liposome encapsulated vitamin A compounds exhibit greater stability and diminished toxicity. Biophys Chem. 1998;73: $155-162$.
6. Atif A, Krishna KP, Farhan JA, et al. Comparative efficacy of liposome-entrapped amiloride and free amiloride in animal models of seizures and serum potassium in mice. Eur Neuropsychopharmacol. 2007:17:227-229.

7. Liang WQ. Biopharmaceutics and Pharmacokinetics. 2nd edition. Beijing: The People's Medical Publishing House; 2006;37.

8. Zheng JM. New Dosage Forms for Transdermal Drug Delivery. Beijing: The People's Medical Publishing House; 1997;102.

9. Zhao K, Wang K, Zhang JR, Cai MZ, Huang FS. Percutaneous penetration of liposomal diclofenac potassium formulation in vivo in rats. Acta Academiae Medicinae Militaris Tertiae. 2004;26(6):513-516.

10. Honeywell-Nguyen PL, Groenink HWW, Graaff de Am, Bouwstra JA. The in vivo transport of elastic vesicles into human skin: efforts of occlusion, volume and duration of application. $J$ Control Release. 2003;90(2):243-255.

11. Qin XQ, Yuan Y, Liu CS, et al. Preparation of LB and its pharmaceutical/ pharmacodynamic characterization. Acta Pharmacol Sin. 2007;28 (11):1851-1858.

12. Zhang L, Jian JB, Yuan Y, Yang BC, Liu C-S. Preparation of brucine liposomes. Chin Trad Pat Med. 2005;27(6):632-637.

13. Zhang GF, Zhu JB, Zhuang Y, Hu J. Study on optimize the preparation and formulation of nimodipine-containing nanoliposome. J Chin Pharm Univ. 2003;34(1):25-28.
International Journal of Nanomedicine

\section{Publish your work in this journal}

The International Journal of Nanomedicine is an international, peerreviewed journal focusing on the application of nanotechnology in diagnostics, therapeutics, and drug delivery systems throughout the biomedical field. This journal is indexed on PubMed Central, MedLine, CAS, SciSearch $\AA$, Current Contents $₫ /$ Clinical Medicine,

\section{Dovepress}

Journal Citation Reports/Science Edition, EMBase, Scopus and the Elsevier Bibliographic databases. The manuscript management system is completely online and includes a very quick and fair peer-review system, which is all easy to use. Visit http://www.dovepress.com/ testimonials.php to read real quotes from published authors. 